\title{
Perancangan Alat Peringatan Dini Bahaya Banjir dengan Mikrokontroler Arduino Uno R3
}

\author{
I. Eka Mulyana*1, Rindi Kharisman ${ }^{2}$ \\ 1,2Teknik Informatika STMIK Tasikmalaya \\ E-mail: ${ }^{* 1}$ nadira dwirahma@yahoo.com, ${ }^{2}$ rindyee@gmail.com
}

\begin{abstract}
Abstrak
Bencana alam merupakan bencana yang tidak dapat di hindari, tetapi walaupun bencana tersebut tidak dapat dihindari, kita bisa mencegah banyaknya jatuh korban akibat bencana tersebut. Contoh nyata pada saat ini yaitu bencana banjir, sudah tidak asing lagi di negeri kita di setiap kota besar yang dilalui sungai besar sering terjadi banjir apabila musim hujan datang, yang setiap tahunnya memakan korban jiwa ataupun materi. Dalam kenyataanya sudah ada alat yang berfungsi sebagai sistem peringatan dini bahaya banjir yang bisa menghitung kecepatan naiknya air, namun di Waduk Darma Kuningan alat tersebut belum ada dan dipakai sebagai peringatan dini bahaya banjir. Maka dari itu timbul ide peneliti untuk membuat salah satu teknologi terapan yaitu alat yang berfungsi untuk peringatan dini bahaya banjir. Penelitian ini dilakukan di Waduk Darma Kuningan untuk pengambilan sampel indikator peringatan dini bahaya banjir. Dengan menggunakan pendekatan kualitatif dan deskriptif. Alat peringatan dini bahaya banjir ini menggunakan Mikrokontroler Arduino Uno $R 3$ dan sensor yang digunakan untuk mengukur ketinggian air yaitu sensor kapasitif, yang nantinya hasil pembacaan dari sensor kapasitif akan ditampilkan pada sebuah display Lcd $16 \times 2$ character.
\end{abstract}

Kata Kunci - Alat peringatan dini, Mikrokontroler Arduino U

\begin{abstract}
Natural disaster is a disaster that can not be avoided, but even if the disaster can not be avoided, we can prevent many fall victims of the disaster. A concrete example is the current flood disaster, is not foreign in our country in every major city through which the great river often floods when the rains come, which annually casualties or materiall. In fact there are already tools that serves as an early warning system of flood hazards that can calculate the speed of the rising water, but at the Waduk Darma Kuningan instruments are not used as an early warning and flood hazard. Thus arose the idea of the researcher to make one of the applied technology is a tool that works for early warning flood hazard. The research this is from Waduk Darma Kuningan brass for EWI sampling flooding. By using a qualitative approach and descriptive.Arduino Uno microcontroller and sensors are used to measure the water level capacitive sensor, which will result from capacitive sensor readout is displayed on a $16 \times 2$ character lcd display.
\end{abstract}

Keywords - Early Warning Device flooding, Arduino Uno R3 Microcontroller, Sensing Capacitive. 


\section{PENDAHULUAN}

Pada masa sekarang ini bidang elektronika mengalami kemajuan yang sangat pesat dan tidak terlepas pada bidang komputerisasi. Komputer saat ini telah menjadi alat bantu utama bagi manusia dan digunakan bukan hanya untuk menyelesaikan permasalahan di tempat kerja, membuat program atau bermain game, tetapi dapat digunakan sebagai alat untuk memprogram mikrokontroler agar dapat berjalan sesuai dengan fungsinya. Dengan adanya teknologi yang terus berkembang saat ini, maka akan semakin mudah untuk mengetahui apakah tanda-tanda aktifitas itu akan berprospek menjadi bencana alam ataukah dapat dimanfaatkan.

Di Indonesia melalui Kepres Nomor (111/2001) kita mengetahui bahwa penanggulangan bencana dan penanganan pengungsi dikoordinasikan oleh Badan Koordinasi Nasional (Bakornas PBP) di tingkat nasional, Satuan Koordinator Pelaksana (Satkorlak PBP) di tingkat provinsi dan Satuan Pelaksana (Satlak PBP) di tingkat Kabupaten/Kota. Melalui keberadaan institusi ini dapat dibuat kebijakan-kebijakan yang berhubungan dengan Sistem Peringatan Dini, misalnya Prosedur Tetap (Protap), Petunjuk Pelaksana (Juklak) dan Mekanisme Kerja. Dengan demikian Sistem Peringatan Dini sebagai mata rantai antara tindakan kesiapsiagaan dengan kegiatan tanggap darurat akan menghasilkan kegiatan respon yang mengarah kepada penanggulangan kerugian akibat bencana sehingga korban akibat bencana dapat dikurangi[1]. Bencana alam merupakan bencana yang tidak dapat di hindari, tetapi walaupun bencana tersebut tidak dapat dihindari, kita bisa mencegah banyaknya jatuh korban akibat bencana tersebut. Contoh nyata pada saat ini yaitu bencana banjir, sudah tidak asing lagi di negeri kita di setiap kota besar yang dilalui sungai besar sering terjadi banjir apabila musim hujan datang, yang setiap tahunnya memakan korban jiwa ataupun materi. Karena disebabkan belum adanya alat yang berfungsi sebagai sistem peringatan dini bahaya banjir yang bisa menghitung kecepatan naiknya air. Maka dari itu timbul ide peneliti untuk membuat salah satu teknologi terapan yaitu alat yang berfungsi untuk peringatan dini bahaya banjir.

Berdasarkan latar belakang tersebut maka dapat dirumuskan permasalahan sebagai berikut:

a. Bagaimana cara merancang perangkat keras sistem peringatan dini bencana banjir?

b. Desain antar muka perangkat keras yang cocok untuk warning system.

c. Bahasa pemrograman apa yang akan digunakan untuk memprogram Mikrokontroler Arduino Uno R3.

d. Bagaimana cara kerja dari alat peringatan bahaya banjir?

Dalam penelitian yang telah dilakukan sebelumnya bahwa untuk memonitoring ketingian air menggunakan sensor kapasitif yang di buat menggunakan 2 buah kapasitor dengan menambahkan FSK demodulator dan dihubungkan dengan Mikrokontroler berbasis Atmega 16. Dari hasil pengujiannya sistem mampu memonitoring ketinggian air laut dengan rata - rata error yang dihasilkan sekitar 33,3\%. Terhadap data yang ditampilkan pada program yang di buat pada IDE Delphi sebagai cara untuk memonitoring ketinggian air laut. Dari sedikit penjelasan diatas maka penelitian ini akan mengembangkan sensor kapasitif sebagai sensor pengukur ketinggian air yang akan diterapkan pada sistem peringatan dini bahaya banjir[2].

Adapun maksud dari penelitian ini adalah untuk membuat salah satu teknologi yang dapat memperingatkan dini bahaya banjir. Penelitian ini bertujuan untuk membuat suatu rancang bangun perangkat keras yang dapat mendeteksi ketinggian air yang dihitung dalam satuan centimeter untuk dijadikan acuan sebagai peringatan dini bahaya banjir, serta program pendukung rangkaian untuk mengontrol perangkat kerasnya.

\subsection{Mikrokontroller Arduino Uno R3}

Mikrokontroler sebuah pengembangan lebih lanjut mengenai mikroprosesor adalah mikrokontroler. bila dalam penggunaannya, mikroprosesor membutuhkan RAM (Random Akses Memory) dan ROM (Read Only Memory) untuk membuat suatu alat yang sederhana. 
Akan tetapi dalam sebuah chip Mikrokontroler, piranti-piranti tersebut telah terintegrasi cukup lengkap didalam nya, bahkan sekarang mikrokontroler ada yang memiliki piranti-piranti tambahan lain yang terintegrasi di dalamnya, seperti ADC (Analog Digital Converter), RTC (Real Time Clock), dan lain-lain. Penggunaan mikrokontroler dapat mengurangi komponen yang akan digunakan bila kita akan membuat suatu alat atau rangkaian elektronik[3]. Arduino adalah sebuah papan mikrokontroler yang sudah didesain dan dibuat oleh salah satu perusahaan dari Italia yang memudahkan pengguna dalam mengembangkan proyek-proyek automasi dan mikrokontroler lainnya dengan mudah dan bersifat open source[4].

\subsection{Arduno IDE (Integrated Development Environment)}

Software arduino yaitu berupa software processing yang digunakan untuk menulis program kedalam Arduino Uno, merupakan penggabungan antara bahasa C++ dan Java. Software Arduino dapat di-install di berbagai operating sistem seperti Linux, Mac OS, Windows. Software IDE (Integrated Development Environment) Arduino Uno terdiri dari tiga bagian yaitu:

a. Editor program, untuk menulis dan mengedit program dalam bahasa processing. Listing program pada Arduino disebut Sketch.

b. Compiler. Modul yang berfungsi mengubah bahasa processing (kode program) kedalam kode biner, karena kode biner adalah bahasa satu-satunya bahasa program yang dipahami oleh Mikrokontroler.

c. Uploader. Modul yang berfungsi memasukan kode biner kedalam memori Mikrokontroller.

Struktur perintah pada arduino secara garis besar terdiri dari dua bagian yaitu void loop. Void setup berisi perintah yang akan dieksekusi hanya satu kali sejak arduino dihidupkan sedangkan void loop berisi perintah yang akan di eksekusi berulang-ulang selama Arduino dinyalakan [4].

\subsection{Sensor Kapasitif}

Kapasitor adalah salah satu komponen pada rangkaian listrik yang dapat menyimpan dan melepas energi listrik dalam bentuk muatan-muatan listrik. Saat pertama kali dihubungkan dengan sumber listrik, kapasitor akan mengisi dirinya dengan muatan-muatan listrik, peristiwa iniliah yang disebut dengan proses charging. Setelah penuh, kapasitor akan menghentikan arus listrik didalamnya sehingga rangkaian listrik akan bersifat open. Namun saat sumber listrik dimatikan dari rangkaian, kapasitor dapat bersifat sebagai sumber listrik dengan cara melepas muatan listrik kepada rangkaian peristiwa ini disebut discharging. Kapasitor umumnya terbuat dari dua konduktor yang diantaranya terdapat materi dielektrik seperti kaca, plastik. Umumnya bahan dielektrik adalah bahan isolator atau bahan yang tidak bisa menghantarkan listrik.namun akibat adanya aliran listrik yang merupakan aliran elektron, atom penyusun dielektrik menjadi tidak seimbang dan akhirnya menimbulkan muatan-muatan listrik. Sehingga setiap bahan dielektrik memiliki nilai permitivitas masing-masing yang akhirnya mempengaruhi nilai kapasitansi[5]. Perhitungan kapasitansi pada parallel plate:

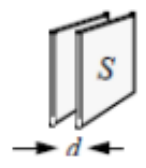

$$
C=\frac{\varepsilon_{0} \varepsilon_{r} S}{d}=8.854 \cdot 10^{-12} \cdot \frac{\varepsilon_{r} S}{d} \text { farads, meters }
$$

- $S=$ Area / Luas

- $D=$ jarak kedua plat.

- $\nabla_{\mathrm{r}}=$ Relative permittivity/ Dielectric Constant 


\subsection{Breadboard}

Project board atau yang sering disebut breadboard adalah dasar kontruksi sebuah sirkuit elektronik dan merupakan prototype dari suatu rangkaian elektronik. Istilah ini sering merujuk pada jenis papan tempat merangkai komponen, dimana papan ini tidak memerlukan proses menyolder. Karena papan ini tidak memerlukan solder sehingga dapat digunakan kembali, dan dengan demikian dapat digunakan untuk prototype sementara serta membantu dalam bereksperimen desain sirkuit elektronika[6].

\section{METODE PENELITIAN}

Perancangan suatu sistem yang akan dibuat merupakan suatu tahapan yang sangat penting dalam membuat suatu program ataupun melanjutkan ke langkah selanjutnya, karena dengan perencanaan tersebut diharapkan mendapatkan hasil yang baik dan maksimal[7]. Dalam perancangan sistem yang peneliti buat adalah suatu alat yang dapat digunakan untuk memperingatkan dini adanya bahaya banjir dan mengetahui kecepatan naiknya air ke permukaan dengan demikian, peneliti membuat perancangan sistem baru berbasis teknologi otomatis dan membagi blok-blok diagram untuk masing-masing komponen yang nantinya akan diintegrasikan menjadi suatu kesatuan dan menjadi alat yang dapat berfungsi sebagaimana yang diharapkan.

\subsection{Analisis Kebutuhan Hardware dan Software}

Dalam pembuatan alat peringatan dini bahaya banjir ini, membutuhkan beberapa perangkat keras (hardware) baik Mikrokontroler maupun komponen elektronik lainnya. Berikut ini adalah daftar komponen yang dibutuhkan.

Tabel 1. Komponen yang dibutuhkan

\begin{tabular}{|l|c|c|}
\hline \multicolumn{1}{|c|}{ Komponen elektronik } & Jumlah & Satuan \\
\hline Mikrokontroler Arduino & 1 & Pcs \\
\hline Breadboard & 1 & Pcs \\
\hline Potensiometer & 1 & Pcs \\
\hline Resistor 100 KOhm & 1 & Pcs \\
\hline Lcd 16x2 & 1 & Pcs \\
\hline PCB untuk sensor & 1 & Pcs \\
\hline Buzzer & 1 & Pcs \\
\hline Kabel Jumper & 1 & Pcs \\
\hline
\end{tabular}

Untuk dapat menjalankan sistem pada alat peringatan dini bahaya banjir, yang perlu diperhatikan bukan hanya perangkat kerasnya saja, tetapi juga perangkat lunaknya (Software) sebab Mikrokontroler tidak akan bekerja sesuai dengan yang diharapkan tanpa adanya intruksiintruksi program yang dimasukan kedalam Mikrokontroler tersebut. Dengan adanya intruksiintruksi program yang telah ditanamkan didalam alat tersebut sehingga Mikrokontroler ini dapat menjalankan fungsinya yaitu mengontrol atau mengatur jalannya sistem keseluruhan alat peringatan dini bahaya banjir. Software Arduino yaitu berupa software IDE (Integrated Development Environment) processing yang digunakan untuk menulis program kedalam Arduino Uno, merupakan penggabungan antara bahasa C++ dan Java. Software arduino dapat di-install di berbagai sistem operasi seperti Linux, Mac OS, Windows. 
Citec Journal, Vol. 1, No. 3, Mei 2014 - Juli 2014

\subsection{Perancangan Alat Peringatan Dini Bahaya Banjir}

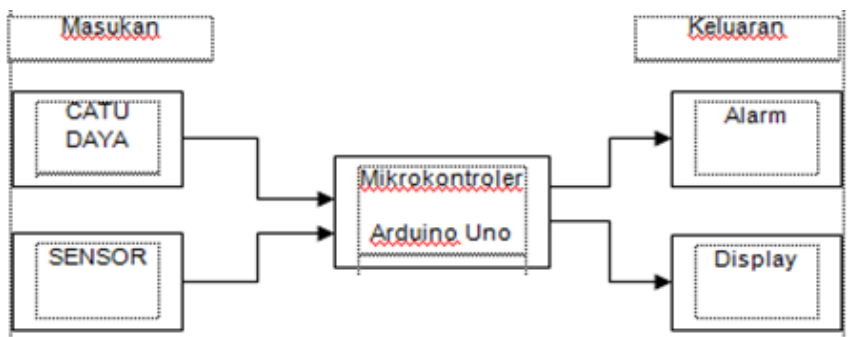

Gambar 1. Blok Diagram Rangkaian Alat Peringatan Dini Bahaya Banjir

Pada gambar 1 dapat dijelaskan blok pertama terdapat blok masukan. Dimana pada blok ini terdapat catu daya yang akan menyuplai daya listrik sebesar 7-9 Volt untuk Mikrokontroler Arduino, pada blok masukan terdapat juga sensor kapasitif, sensor ini akan digunakan sebagai sensor untuk mengukur ketinggian air dan juga sebagai acuan untuk indikator sistem peringatan dini bahaya banjir. Pada blok kedua yaitu keluaran atau output terdapat Alarm yang berfungsi membunyikan sirine sebagai tanda adanya banjir, alarm ini sementara dibuat menggunakan Buzzer untuk simulasi alat peringatan dini bahaya banjir. Dalam alat peringatan dini banjir juga ditanamkan sebuah LCD untuk menampilkan informasi tentang kenaikan dan kecepatan air yang dihasilkan dari sensor kapasitif.

\subsubsection{Perancangan Sensor Kapasitif}

Tahap pertama dalam pembuatan alat peringatan dini bahaya banjir adalah pembuatan kapasitor sebagai sensornya. Dengan perancangan sensor yang didahulukan, maka tahap perancangan selanjutnya dapat disesuaikan. Pada tugas akhir ini rancangan 2 buah PCB dengan ukuran $20 \mathrm{~cm} \times 1.5$ tembaga yang terdapat dapat pada PCB, maka yang nantinya dua plat lempengan tembaga tersebut berfungsi sebagai kapasitor. Jarak antara dua plat lempengan tembaga tersebut adalah $1 \mathrm{~cm}$. kedua plat dihubungkan dengan spiser dengan panjang $1 \mathrm{~cm}(\mathrm{~d})$. akrilik berbentuk U kotak berfungsi sebagai kedudukan sensor kapasitif. Pada bagian tengah lempengan tembaga diberikan kabel yang nantinya terhubung pada pin 6 dan pin 10 pada Mikrokontroler Arduino sebagai pengontrol timing kapasitor, dari hasil deskripsi diatas maka rancangan dituangkan pada gambar dibawah ini.
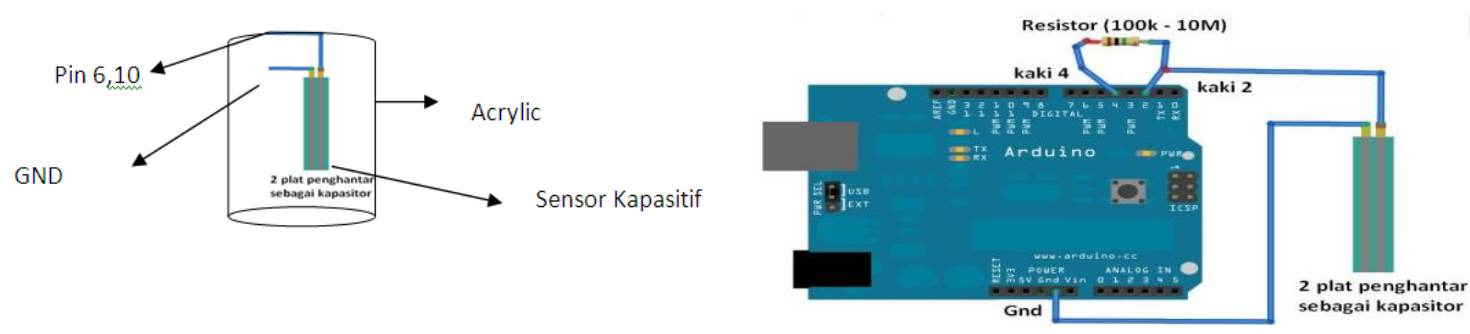

Gambar 2. Desain Kapasitif sensor

Rumus untuk mencari nilai kapasitansi nya:

$\mathrm{C}=$ Capasitif

$$
C=(\text { constant } x A) / d
$$

Konstanta dielektrik= constanta, untuk constanta dielektrik air 80,

$\mathrm{A}=$ Luas penampang yang terendam air

$\mathrm{D}=$ Jarak antara kedua plat 
Nilai kapasitansi diatas diperoleh dari teori, sedangkan secara prakteknya (Mikrokontroler Arduino), nilai kapasitansinya diperoleh dari pendeteksian besarnya waktu yang diperlukan untuk pengisian kapasitor $(=\mathrm{T})$, yang dapat dinyatakan secara pendekatan sebesar T=1,1 x R x C. Dengan nilai resistansi sebesar $100 \mathrm{KOhm}$, dan nilai T dalam waktu ms (millisecond) seperti yang akan terlihat dijendela serial monitor, maka akan diperoleh nilai Capasitansinya.

\subsubsection{Perancangan Catu Daya}

Rangkaian power supply atau pencatu daya lebih sering disebut juga adaptor, merupakan sebuah bagian dari rangkaian elektronika yang berfungsi sangat fital. Sebuah rangkaian elektronika dapat bekerja apabila ada rangkaian pendukung yang menyupply atau pendukung catu dayanya. Dalam alat peringatan dini banjir memerlukan dua catu daya yang berfungsi untuk menyupply komponen lainnya. Yang pertama adaptor yang berfungsi sebagai penyearah yaitu rangkaian yang mengubah sinyal bolak-balik (AC) menjadi sinyal searah (DC), yang kedua yaitu Baterai, baterai yang digunakan dalam alat peringatan dini bahaya banjir berfungsi untuk menyimpan energy listrik dari alternator saat alat peringatan dini dihidupkan sehingga baterai siap pakai. Jenis baterai yang digunakan dalam alat ini yaitu Lithium Ion (Liion) karena memiliki banyak kelebihan diantaranya lebih ringan, kuat dan awet dibandingkan baterai NiMH (nickel-metal hydride). Berikut Rangkaian dasar Adaptor dan baterai.

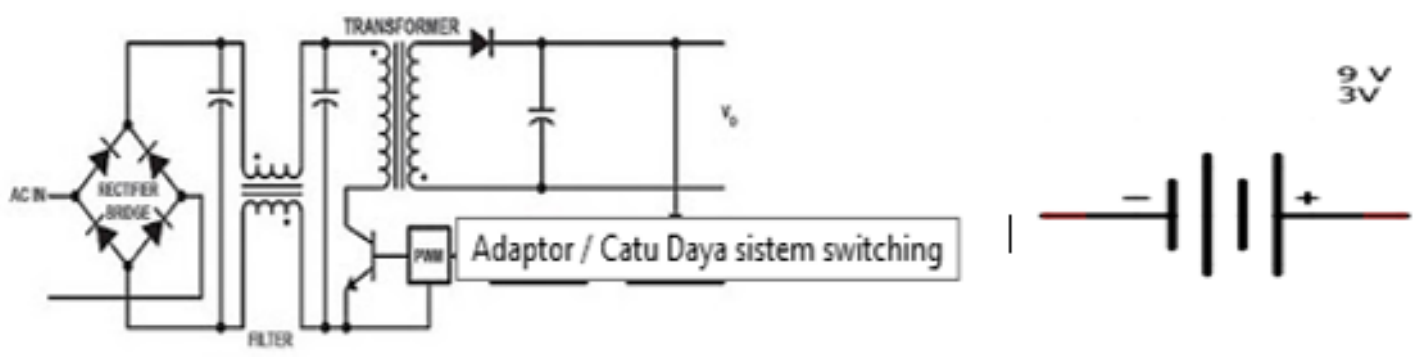

Gambar 3. Rangkaian dasar adaptor \& Scematic Baterai

\subsubsection{Perancangan LCD (Liquid Crystal Display) $16 \times 2$}

Salah satu modul yang terhubung dengan Mikrokontroler adalah modul LCD, modul LCD digunakan sebagai display untuk menampilkan informasi tentang kenaikan air yang dihasilkan dari pembacaan sensor secara otomatis. Untuk dapat menampilkan informasi pada LCD.

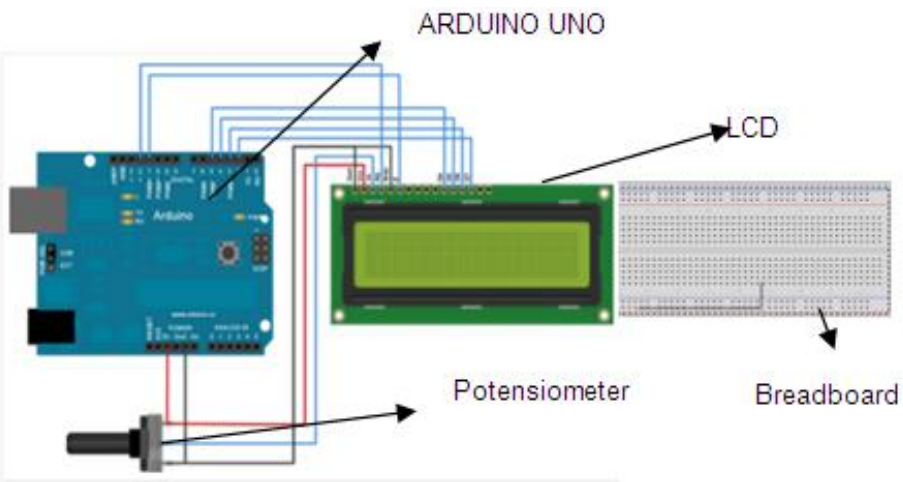

Gambar 4. Koneksi Arduino dengan LCD 
Gambar 4 diatas menjelaskan tentang koneksi Mikrokontroler Arduino dan LCD, yaitu:

a. Pin RS (kaki 4) disambungkan dengan pin Arduino digital pin 12.

b. Pin E(kaki 6) disambungkan dengan pin Arduino digital pin 11.

c. Pin D4 (kaki 11) disambungkan dengan pin Arduino digital pin 5.

d. Pin D5 (kaki 12) disambungkan dengan pin Arduino digital pin 4.

e. Pin D6 (kaki 13) disambungkan dengan pin Arduino digital pin 3.

f. Pin D7 (kaki 14) disambungkan dengan pin Arduino digital pin 2.

g. Sambungkan Potensiometer $10 \mathrm{KOhm} k \mathrm{ke}+5 \mathrm{v}$ dan GND, dan pin LCD 3 Potensiometer.

h. Pin $5(\mathrm{R} / \mathrm{W})$ ke Ground.

\subsubsection{Perancangan Buzzer (Alarm)}

Pada alat ini Buzzer digunakan sebagai alat untuk indikator bunyi sementara pada simulasi yang akan dibuat pada proses selanjutnya, Buzzer digunakan sebagai penanda apabila kenaikan air sudah mencapai batas maksimum yang telah ditentukan berdasarkan skala batas maksimum. Sedangkan untuk penanda bunyi alarm sebenarnya akan menggunakan speaker yang lebih besar yang mampu menghasilkan suara yang lebih keras. Buzzer yang digunakan untuk simulasi alat peringatan dini bahaya banjir yaitu piezzo buzzer, karena dalam penerapannya dapat menghasilkan bunyi yang bervariatif. Untuk menghubungkan buzzer dan Mikrokontroler Arduino terdapat 2 kabel yang ada pada buzzer, dan ditandai oleh kabel warna merah dan warna hitam ini menandakan kabel warna merah positif yang akan dihubungkan pada pin 13 pada arduino dan warna hitam negatif dihubungkan pada pin GND.

\subsubsection{Perancangan Komponen Keseluruhan}

Setelah semua komponen dirangkai satu persatu ke Mikrokontroler kini saat nya menggabungkan seluruh rangkaian menjadi satu, agar dapat berfungsi sebagai Alat Peringatan Dini Bahaya Banjir. Berikut rangkaian secara keseluruhan.

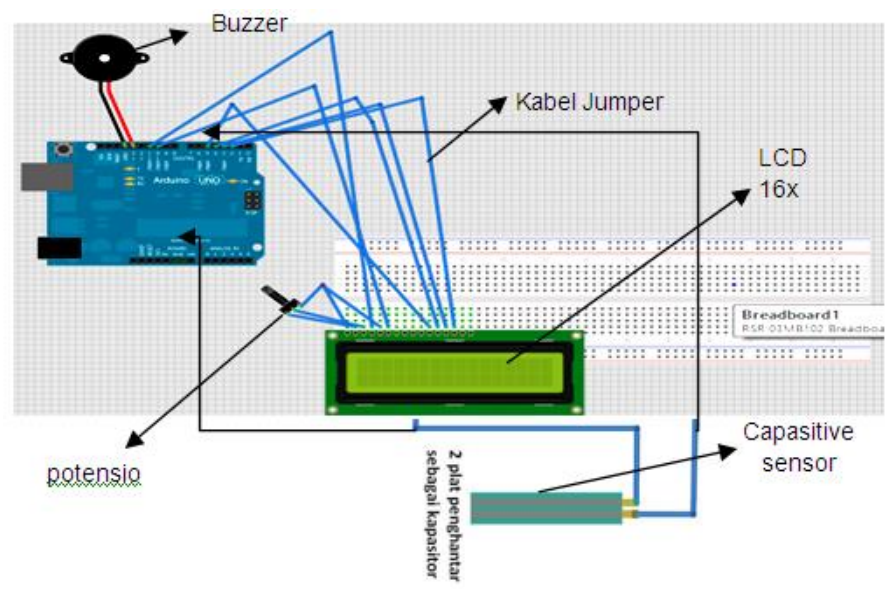

Gambar 5. Desain Alat Peringatan Dini Bahaya Banjir

Setelah peralatan dirancang secara keseluruhan ternyata terjadi perubahan konfigurasi pin komponen yang terhubung ke pin Arduino Uno yaitu pin sensor kapasitif. Berikut adalah konfigurasi pin sensor kapasitif yang terhubung ke Mikrokontroler Arduino.

Tabel 2. Konfigurasi Pin Sensor Kapasitif dan Arduino

\begin{tabular}{|l|l|}
\hline Pin Sensor Kapasitif & Pin Mikrokontroler Arduino \\
\hline Pin + (positif) Kabel warna Biru & Pin 6 dan 8 (PWM) \\
\hline Pin - (negative) Kabel warna Putih & Pin GND (Ground) \\
\hline
\end{tabular}


Tabel 2 diatas menjelaskan tentang:

a. Pin positif yang ditandai dengan warna biru terhubung pada pin 6 dan 8 PWM dengan diberi tahanan sebesar $100 \mathrm{KOhm}$ pada Mikrokontroler Arduino.

b. Pin negatif yang ditandai dengan warna putih dihubungkan pada pin GND pada Arduino.

\subsubsection{Diagram Alur Sistem Alat Peringatan Dini Bahaya Banjir}

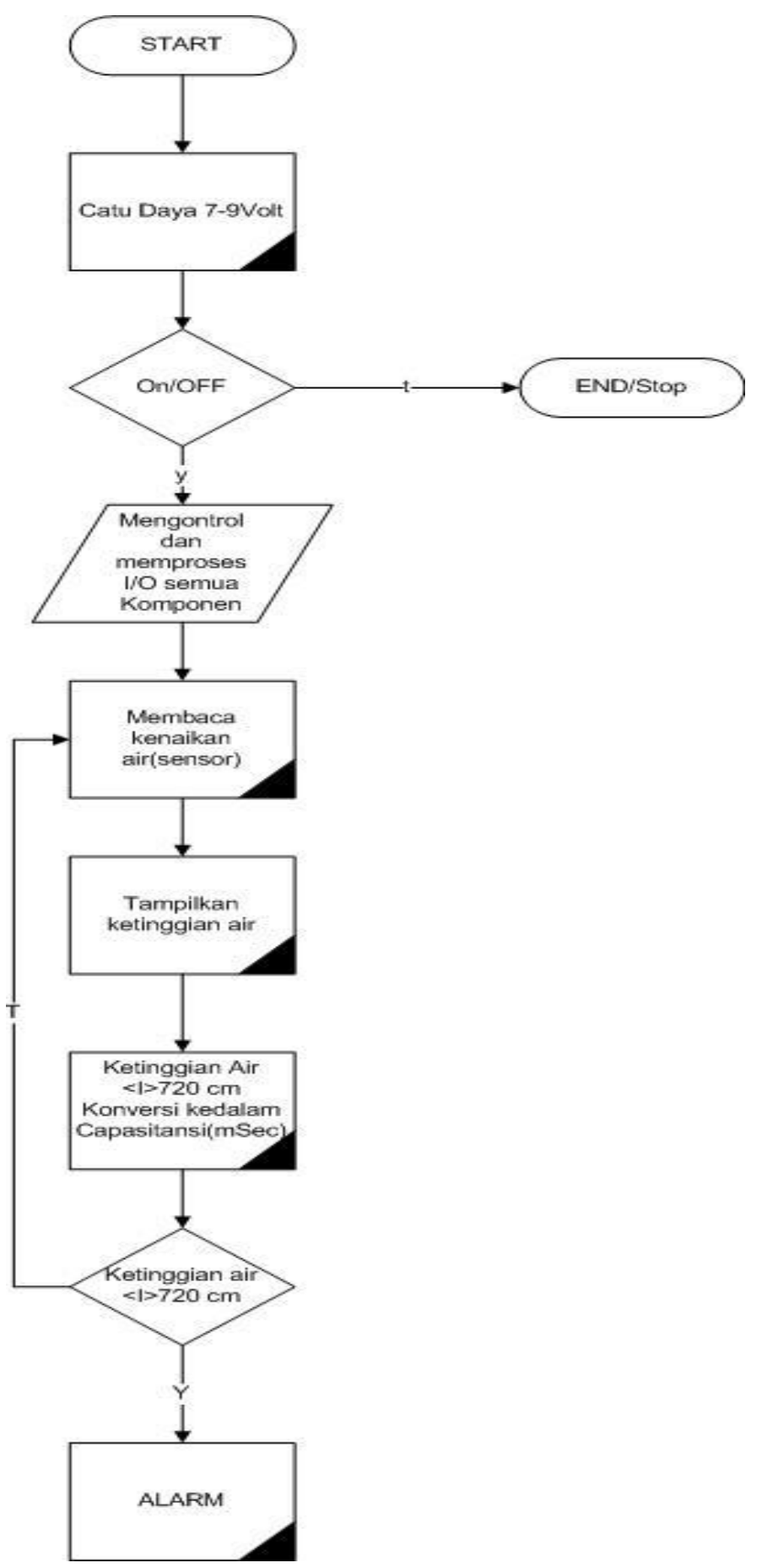

Gambar 6. Flowchart Sistem Alat Peringatan Dini Bahaya Banjir 


\section{HASIL DAN PEMBAHASAN}

Percobaan pengujian alat peringatan dini bahaya banjir dibagi menjadi beberapa bagian yaitu pengujian perangkat keras yang meliputi uji sensor, Display, uji alarm atau sirine (buzzer) dan uji rangkaian keseluruhan sistem minimum alat peringatan dini bahaya banjir dan pengujian perangkat lunak atau program yang akan di upload ke Mikrokontroler Arduino Uno.

\subsection{Pengujian Sensor Kapasitif}

Pengujian pada sensor dilakukan dengan cara memasang langsung sensor ke tempat penelitian yaitu Waduk. Untuk pengujian sensor bekerja atau tidak nya, maka pengujian pertama dilakukan disaat sensor belum terkena air apakah menghasilkan suatu nilai kapasitansi atau tidak. Berikut gambar nilai kapasitansi sensor sebelum terkena air.

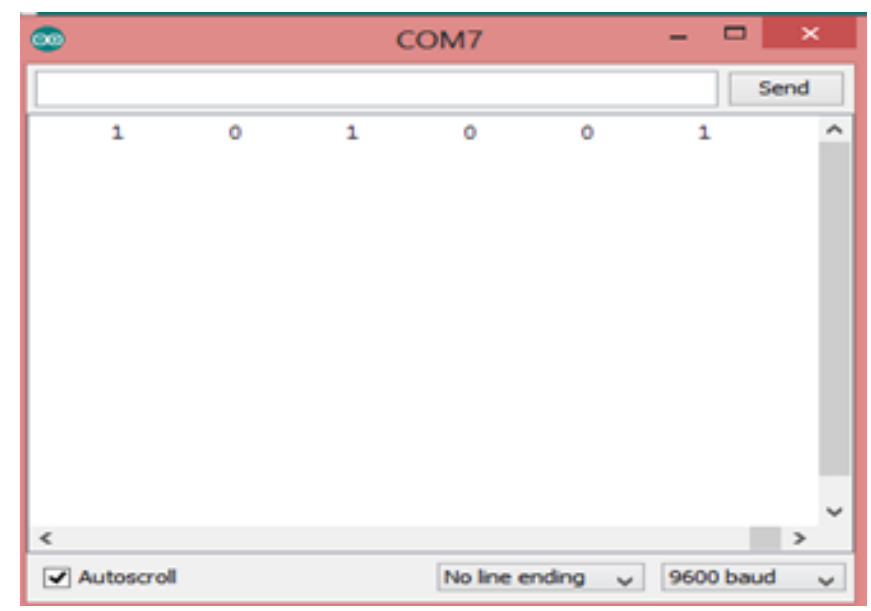

Gambar 7. Nilai Kapasitas Sensor

Dari gambar di atas nilai kapasitansi yang dihasilkan dari pengujian sensor pada serial monitor IDE Arduino yang belum terkena air maka nilainya yaitu antara 1 dan 0. Berarti dalam hal ini sensor sudah berjalan sebagaimana perancangan sensor kapasitif yang telah dilakukan sebelumnya.

Untuk selanjutnya dilakukan pengujian sensor menggunakan air yang dituangkan kedalam wadah secara perlahan berdasarkan pengukuran $\mathrm{cm}$ yang dilakukan secara manual dan akan terlihat nilai kapasitansinya dalam satuan ketinggian air perecentimeternya.

Tabel 3. Hasil pengujian pengukuran kapasitansi ketinggian air

\begin{tabular}{|c|c|c|}
\hline No & $\begin{array}{c}\text { Ketinggian Air } \\
(\mathrm{cm})\end{array}$ & $\begin{array}{c}\text { Nilai Rata-Rata } \\
\text { Kapasitansi }\end{array}$ \\
\hline 1. & 2 & 24 \\
\hline 2. & 4 & 131 \\
\hline 3. & 6 & 266 \\
\hline
\end{tabular}

Hasil pengujian diatas dilakukan secara acak dalam menuangkan air kedalam wadah, karena harus mendapatkan nilai kapasitansi yang signifikan dalam peningkatan nilai nya.

\subsection{Pengujian Display LCD 16x2 Character}

Pengujian display dilakukan dengan memasukan coding sederhana sementara kedalam mikrokontroler yang sudah terhubung dengan display, yang sebelumnya sudah dilakukan perancangan antara Arduino Uno dan LCD. Berikut gambar hasil pengujian Display. 


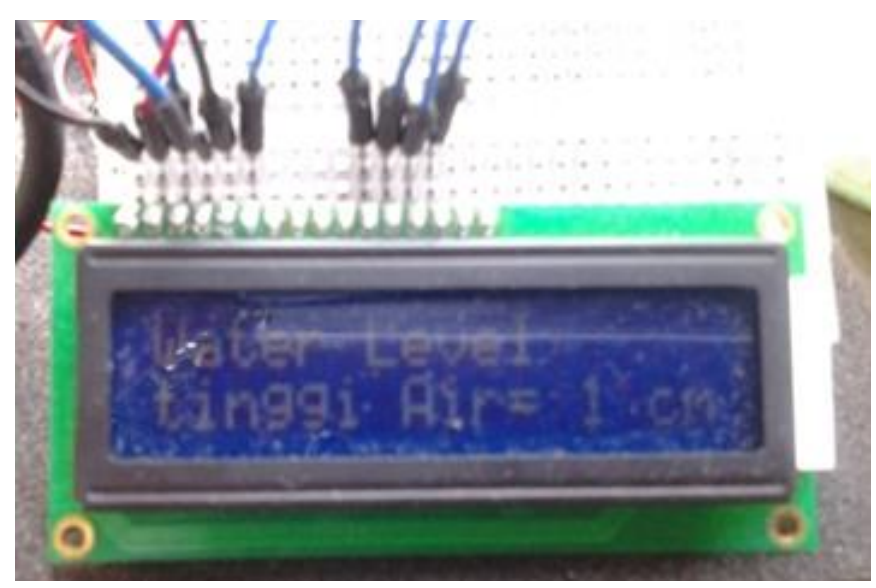

Gambar 8. Hasil pengujian display Lcd 16x2

Dari gambar 2 di atas diketahui bahwa Display LCD sudah dapat menyala, dan LCD juga dapat menerima output nilai kapasitansi dari sensor kapasitif yang sudah di konversi kedalam $\mathrm{cm}$.

\subsection{Pengujian Alarm (Buzzer)}

Pengujian alarm dilakukan dengan cara mengukur ketinggian air dengan sensor maka diambil satu kondisi jika ketinggian air mencapai batas maksimum maka Buzzer alarm akan menyala High bernilai 1 atau True apabila ketinggian air kurang dari batas maksimum maka buzzer diam Low bernilai 0 atau false. Dalam hal ini pengujian buzzer bersifat simulasi karena batas maksimum yang diambil dari sensor hanya $7 \mathrm{~cm}$, sedangkan yang sebenarnya di Waduk Darma kuningan batas maksimum nya adalah $720 \mathrm{~cm}$. Karena pengujian buzzer sifat nya bunyi, maka akan dibuktikan dengan cara membuat tabel pengujian Buzzer.

Tabel 3. Pengujian Alarm Buzzer

\begin{tabular}{|c|c|c|c|c|}
\hline $\begin{array}{c}\text { Percobaan } \\
\text { Ke- }\end{array}$ & $\begin{array}{c}\text { Ketinggian } \\
\text { Air }(\mathrm{cm})\end{array}$ & \multicolumn{2}{|c|}{ Nilai } & $\begin{array}{c}\text { Alarm } \\
(\text { Buzzer })\end{array}$ \\
\hline 1. & 0 & 0 & False & Low \\
\hline 2. & 2 & 0 & False & Low \\
\hline 3. & 4 & 0 & False & Low \\
\hline 4. & 7 & 0 & False & Low \\
\hline 5. & 12 & 1 & True & High \\
\hline
\end{tabular}

\subsection{Pengujian Program}

Pengujian program di lakukan untuk mengecek program yang dibuat sebelumnya apakah program yang dibuat sudah berhasil terkompilasi atau tidak, karena apabila progam masih terjadi error maka program tersebut tidak akan bisa terupload ke Mikrokontroler sehingga alat peringatan dini bahaya banjir tidak akan berjalan sesuai dengan kegunaan. Berikut gambar hasil coding program pada IDE Arduino.

Dari gambar 9 berikut menunjukan bahwa program telah sukses di compile dan siap untuk di upload ke Mikrokontoler ini ditandai dengan keterangan bahwa data coding 32,256 sukses dan diterima oleh Microchip. 


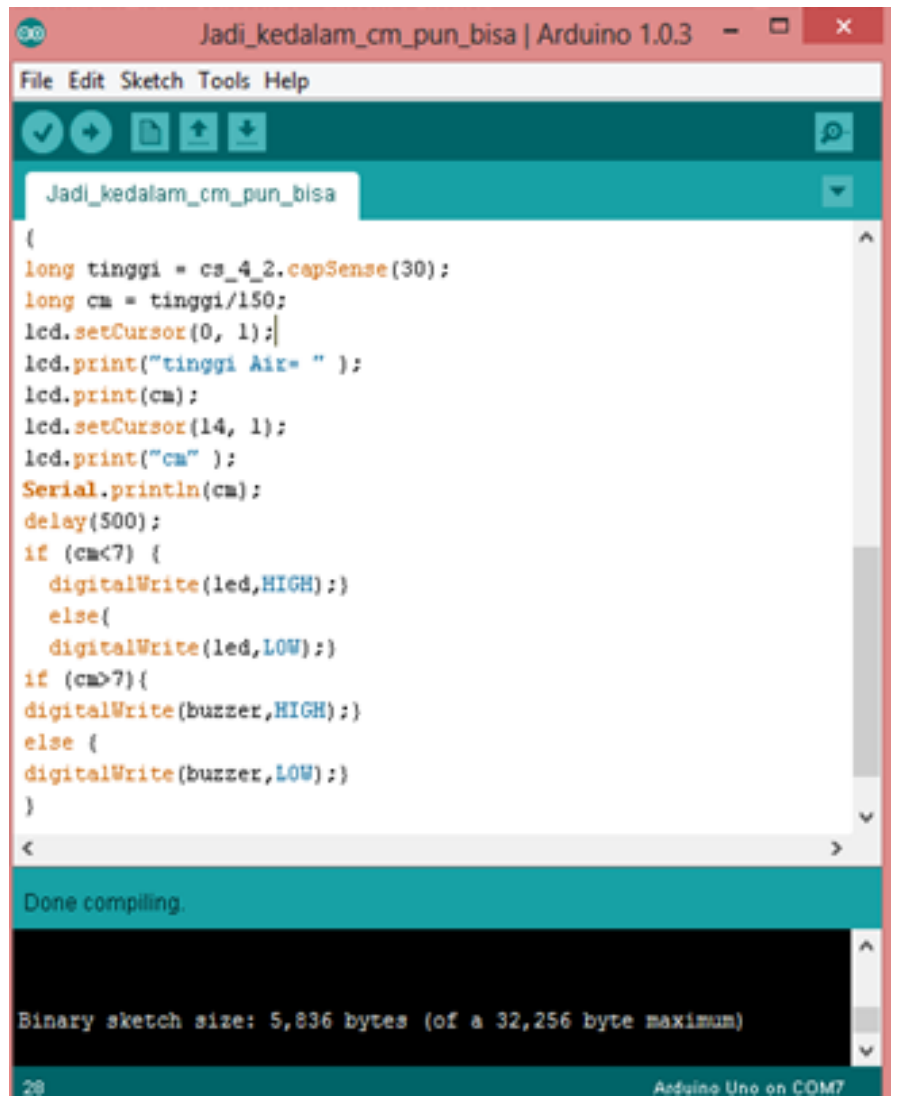

Gambar 9. Compiling Program

Dari hasil pengujian yang telah dilakukan dapat diketahui bahwa alat peringatan dini bahaya banjir dapat ditempatkan di berbagai tempat seperti bendungan, posko pengendalian ketinggian air sungai dan Waduk. Karena dengan desain interface yang sangat sederhana dan simpel mudah dipahami dalam pembacaan ketinggian air, inilah kelebihan produk yang dibuat. Semua komponen alat peringatan dini bahaya banjir telah terintegrasi dengan lengkap dan siap digunakan dalam kondisi air apapun tanpa akan merusak sensor karena dalam penempatanya sensor dilengkapi pelindung untuk mencegah terjadinya kerusakan. Sedangkan alat Mikrokontrolernya sendiri ditempatkan jauh dari jangkauan banjir karena diletakan di tempat yang berbeda dalam penerapannya dilapangan. Dalam pengoperasiannya alat peringatan dini bahaya banjir ini tidak memerlukan daya yang cukup besar, dikarenakan daya listrik yang diperlukan untuk mikrokontrolernya sendiri, hanya berkisar antar 7-9 Volt, ini bisa didapat dari baterai yang dapat dicas ulang sehingga apabila terjadi padam listrik, alat ini akan terus beroperasi hingga baterainya habis.

\section{KESIMPULAN}

Kesimpulan dari keseluruhan yaitu pengujian yang dilakukan menunjukan bahwa alat peringatan dini bahaya banjir dapat bekerja sesuai dengan yang diharapkan, yaitu memberikan peringatan dini bahaya banjir kepada lingkungan sekitar bila terjadi banjir dengan cara pengaktifan otomatis alarm peringatan dini bahaya banjir. Berdasarkan proses implementasi, pengujian alat dan evaluasi pada alat peringatan dini bahaya banjir dapat ditarik kesimpulan sebagai berikut:

1. Pengintegrasian alat antara Mikrokontroler Arduino sensor kapasitif dan buzzer telah berhasil dilakukan ditandai dengan bekerjanya alat sesuai program yang telah dibuat menggunakan bahasa pemrograman $\mathrm{C}$. 
2. Pemanfaatan sensor kapasitif sebagai sensor untuk mendeteksi ketinggian air telah berhasil dilakukan.

3. Pembacaan sensor kapasitif kurang begitu akurat sehingga sering terjadi sebuah nilai kapasitansi yang selalu berubah-ubah.

4. Membutuhkan bahan dielektrik pembungkus yang baik untuk kapasitor. Hal ini dikarenakan lama-kelamaan akan menimbulkan korosi pada plat kapasitor.

\section{SARAN}

Saran yang dapat diajukan untuk penelitian lebih lanjut mengenai topik ini adalah:

1. Membutuhkan perhitungan yang tepat pada sensor kapasitif untuk mendapatkan hasil perhitungan nilai kapasitansi yang akurat.

2. Harus ada pengembangan lebih lanjut mengenai alat peringatan dini bahaya banjir ini, agar manfaatnya lebih terasa dari segi financial khususnya bagi pengembang maupun sosial umumnya bagi masyarakat.

Alat ini harus dikembangkan dengan menggabungkan sms gateway, agar alat peringatan dini bahaya banjir ini lebih praktis dalam pengoperasian dan informasi yang dihasilkan pun lebih real time.

\section{DAFTAR PUSTAKA}

[1] Arafat, Y., 2007, Konsep Sistem Peringatan Dini di Wilayah Bencana Banjir Sibalaya Kabupaten Donggala, Jurnal SMARTek, Vol 5, No 3, hal 166-173.

[2] Magusti, R., Suwito, Rivai, M., 2006, Sensor Kapasitif Untuk Mengukur Ketinggian Permukaan Air Laut Menggunakan Mikrokontroler, Jurusan Teknik Elektro FTI- ITS, Surabaya.

[3] Rismansyah, D., 2011, Pemberhentian Kereta Secara Otomatis Berbasis Mikrokontroler AT89S51, Skripsi, Jurusan Sistem Komputer, Fakultas Ilmu Komputer Universitas Gunadarma, Jakarta.

[4] Roberts, M. Mc, 2009, Arduino Starter Kit Manual, Earthshine Electronics.

[5] Johanson, 2009, Capacitive Sensing Method and Application. Binus University, Vol 2, No 2, Jakarta.

[6] Graham, B., McGowan, K., 2010, 19 Brain-Branding Bio Hack, McGraw-Hill.

[7] Fauzi, R. R., 2011, Sistem Pengendali Robot Mobil Berbasis Mikrokontroler ATMega16 dengan RJ45, Skripsi, Fakultas Ilmu Terapan Politeknik Telkom, Bandung. 